\title{
Tres reflexiones sobre el pasado proceso electoral
}

Luego de dos meses de celebradas las elecciones para diputados y concejos municipales, nadie pone en duda que las mismas han constituido un elemento de cambio en la dinámica política salvadoreña, primero porque se ha quebrado la hegemonía del partido ARENA en el ejercicio del poder; y, segundo, porque aparentemente cualquier decisión política que afecte a la nación de hoy en adelante será fruto de no pocos - y probablemente difíciles- procesos negociadores y concertadores. En tal sentido, el pasado proceso electoral puede significar mucho para la historia política de este país a mediano plazo; esto depende claramente de la sociedad salvadoreña, pero en especial de los políticos electos, sobre todo en la medida en que puedan comprender el mensaje de la población de manera objetiva, humilde y aleccionadora.

Hasta ahora, mucho se ha hablado del proceso electoral. La mayor parte de las referencias lo califican como una expresión de la voluntad popular y hasta parece un pecado llegar a dudarlo públicamente. Otros señalaron los comicios como la evidencia del deseo de cambio de las mayorías salvadoreñas, incluso, los más partidarios, como el apoyo masivo a las opciones de izquierda. $Y$ es que esta forma de ver las elecciones proviene de aquellos sectores favorecidos por el resultado de las mismas y quienes, en esta oportunidad, no dudan en atribuir legitimidad a un proceso con características que en el pasado los llevaba a cuestionar el alcance de los eventos electorales. Por ello, es importante destacar, en este pequeño comentario, tres reflexiones que parecen ignorarse respecto a los pasados sufragios del 16 de marzo. Estos argumentos no ponen en duda, desde ningún punto de vista, la legalidad de los comicios, pero son útiles para alcanzar un sano principio de realidad que es necesario tener presente en los comportamientos políticos a corto plazo. En la forma que se realizaron las elecciones $y$, en un proceso de transición democrática, el examen de los resultados electorales debe tomar en cuenta no sólo el porcentaje de votos que cada partido obtuvo en las distintas instancias, sino también el número de votos conquistados y cuánto representa esto del potencial de elección de la ciudadanía; lo anterior implica prestar un interés fundamental al insoslayable problema del ausentismo en los sufragios.

En primer lugar, las elecciones celebradas recientemente no pueden considerarse en el sentido estricto como la voluntad popular. En segundo lugar, el comportamiento electoral, registrado el 16 de marzo, no parece ser un voto que apuesta por el cambio de manera decisiva, sino que es mas bien un voto que apuesta por el equilibrio, lo cual es distinto. Finalmente, y en relacion con lo anterior, las pasadas elecciones antes que considerarlas como la expresión del rechazo hacia ARENA o como la manifestación del apoyo hacia el FMLN, deben considerarse como la expresión del recelo de los ciudadanos hacia sus partidos políticos.

Estas afirmaciones pueden parecer juicios radicales sobre la base de un hecho que se ha convertido en normal dentro del tradicional comportamiento electoral de los salvadoreños, como lo es el ausentismo; algunas personas podrán decir que ésta es la conducta típica de la población salvadoreña, en términos políticos, y que, por tanto, las elecciones deben verse desde tal descargo; $s i n$ embargo, el mismo ausentismo constituye una expresión de la crisis del sistema salvadoreño, crisis que 
está marcando fundamentalmente el proceso de transición política.

El resultado de las elecciones, en función de la victoria de un partido o de otro, no puede considerarse como el producto directo de la voluntad popular. Este argumento se apoya en dos datos fundamentales sobre las elecciones. El primero es de orden cuantitativo. Según el reporte final del Tribunal Supremo Electoral, el número máximo de votos válidos alcanzado en los pasados comicios fue de más del millón; en concreto éstos, en la elección de diputados, ascienden a 1,119,471. Ahora bién, si en la actualidad se asume que la población en edad de votar (mayores de 17 años) es de aproximadamente 3 millones ochenta y un mil electores, según la Encuesta de hogares de propósitos múltiples de 1996, se tiene que en el pasado proceso electoral sólo el 36 por ciento de los salvadoreños lo hicieron. En otras palabras, sólo la tercera parte de los ciudadanos con derecho a votar pudieron hacer valer su voto en los pasados comicios; puesto de otra manera, sólo uno de cada tres ciudadanos ejerció plenamente su derecho de elegir a sus autoridades. Lo anterior quiere decir que la elección de los gobernantes municipales y los representantes legislativos se hizo con una porción minoritaria de la ciudadanía y no con la mayor parte de ésta, lo cual cuestiona seriamente la idea de que la ventaja o la victoria de un partido concreto haya sido el producto de la voluntad de la mayor parte de ciudadanos. En todo caso, al ver tales cifras y asumir, como lo sugieren las encuestas de opinión pública, que muchos salvadoreños no votaron por su desconfianza en el proceso y carecer de una preferencia política concreta, entonces el resultado de las elecciones sería producto de la apatía de las mayorías, no de la voluntad popular. La situación es aún más preocupante si se considera que, en estas circunstancias, cualquier partido, incluso los llamados mayoritarios, no alcanzaron siquiera el 15 por ciento de la simpatía ciudadana. Tomando como ejemplo al partido ARENA, que obtuvo el mayor número de votos (un total de 410,537 votos en la elección de concejos municipales), se tiene que este partido sólo recibió el 13.5 por ciento del apoyo de los adultos salvadoreños; el resto de partidos recibió apoyo de una proporción aún menor.

Desde esta perspectiva, ningún partido puede declararse como representante de la mayoría o como la primera fuerza política en la población; asimismo ninguno puede sentirse sólidamente respaldado por el apoyo masivo de los ciudadanos. Esta situación tiene implicaciones serias en el nivel de soporte sobre el que los partidos lanzan sus iniciativas de gobierno y legislación. Con menos del 15 por ciento de apoyo ciudadano, ningún partido se encuentra en posibilidades de llevar a cabo, por sí solo, un plan de gobernabilidad y de desarrollo nacional, mucho menos tiene posibilidades de realizar una "cruzada cívica" con un respetable apoyo ciudadano en favor de un tema de discusión nacional.

Sin embargo, el problema de la voluntad popular en las elecciones recién pasadas no termina en los simples números. El segundo hecho, en que se basa el argumento de que el desenlace electoral no es sinónimo de la voluntad popular, tiene además un sentido cualitativo. No sólo se trata de cuántos ciudadanos no eligieron en esta ocasión sino que también quiénes eran estos ciudadanos.

Los primeros datos de una encuesta postelectoral, así como los resultados obtenidos por el Instituto Universitario de Opinión Pública, sugieren que en el pasado evento electoral tomaron parte los sectores de clase media y clase alta de la población. Es decir, que quienes eligieron en esta oportunidad $-\mathrm{y}$ como en muchas ocasiones anteriores- no fueron los ciudadanos considerados como las mayorías de la población; al contrario, fueron aquéllos que residen en las zonas urbanas del país, que forman parte de los estratos socioeconómicos altos, medio-altos y medio-bajos, y cuya escolaridad llega al bachillerato o la educación universitaria (ver el Cuadro 1). En otras palabras, las personas con menos recursos sociales, con más problemas de supervivencia socioeconómica -es decir, los más pobres-y marginadas de la decisiones políticas que les afectan directamente constituyeron el grupo más grande de ausentistas en las pasadas elecciones. Dicho de otra forma, las tradicionalmente llamadas mayorías de este país fueron el porcentaje menor que votó en el pasado marzo. La importancia de este hecho no radica en un juicio discriminatorio sobre el valor del voto según la posición social de los electores, sino sobre el hecho de que las personas que no asistieron a votar son las que se encuentran más relegadas del ejercicio del poder político y de la participación en las decisiones políticas nacionales. Estas personas, que conforman "las mayorías populares", con más necesidad de compro- 
meter a los representantes políticos, constituyeron paradójicamente el grupo que menos expresó su preferencia política y su opción de gobernabilidad en el proceso electoral.

\begin{tabular}{lc} 
Cuadro 1 \\
Composición de los votantes del 16 de marzo en \\
el municipio de San Salvador según variables \\
\hline Variables & Porcentajes \\
\hline
\end{tabular}

Sexo

Masculino

58.1

Femenino

41.9

Edad

18 a 25 años

19.2

26 a 40 años

38.2

41 a 55 años

27.9

56 años o más

14.6

Nivel educativo

Ninguno

3.8

Primaria

13.8

Plan básico

12.3

Bachillerato

26.6

Técnico

5.7

Universitario

37.7

Fuente: IUDOP, Boletín de prensa, año XII, número 2.

En un país que transita hacia la democracia es fundamental que las elecciones se conviertan en un espacio abierto para la manifestación de la voluntad popular, esto es, de aquéllos que usualmente no disponen de recursos sociales para hacerlo de otra manera. Si esto no se cumple, si al final quienes se manifiestan son los mismos sectores ligados a aquéllos que detentan el poder político y económico, el alcance del proceso será muy limitado y el carácter "popular" de dicha voluntad, muy cuestionable. La gobernabilidad de un país, tanto el rumbo como el tipo de desarrollo que se implementen, requiere del apoyo de los ciudadanos a sus autoridades y representantes, así como también un compromiso de éstos para con aquéllos. Con porcentajes de apoyo ciudadano por debajo del 15 por ciento, concen- trados en algunos sectores, es difícil afirmar que las elecciones anteriores hayan sido "la expresión más genuina de la voluntad popular".

En cualquier caso, no todo es negativo en el sistema político salvadoreño después de las elecciones. Aunque es innegable la necesidad de contar con institutos políticos apoyados popularmente, no es menos cierto que la actual configuración de bloques políticos, caracterizada no por la fortaleza de unos sino por la debilidad de todos, puede ser útil en la conformación de una práctica más democrática en la discusión y la dinámica política salvadoreña; sobre todo, en la búsqueda de la concertación en lugar de la imposición, en la medida en que los políticos comprendan con humildad que la voluntad popular, por el momento, no reside en ninguno de los partidos.

El s̄egundo hecho, que es necesario subrayar respecto al proceso electoral, tiene relación con el carácter de la elección. Se dice que las elecciones recién pasadas fueron unas elecciones de cambio; esto puede ser cierto desde la perspectiva de la correlación final de las fuerzas políticas, pero no lo es desde la perspectiva de la conducta electoral. El comportamiento electoral de la población en el pasado 16 de marzo no parece tener la intención de ser un voto que apuesta por el cambio de manera decisiva, sino que más bien busca el equilibrio de la fuerzas políticas por el rechazo moderado a una opción de gobierno. Detrás de esta tesis se encuentra la consideración del elevado ausentismo en las elecciones.

Según la teoría de las ciencias políticas sobre la conducta en los sufragios, las elecciones de 
cambio se caracterizan por una elevada concurrencia electoral, en la cual el ausentismo se vereducido a la mínima expresión. Algunos ejemplos son los comicios sudafricanos de 1994 que marcaron el fin de la transición de un Estado segregacionista a uno democrático; tales comicios registraron una asistencia mayor del 90 por ciento y como resultado salió electo el primer presidente de color, en esa nación de mayoría negra. Otro ejemplo, más reciente, de elecciones de cambio lo constituyen los pasados comicios británicos ganados contundentemente por los laboristas, con un porcentaje de participación arriba del 70 por ciento.

Ciertamente, las elecciones del pasado 16 de marzo pueden significar un cambio en la composición de la asamblea legislativa y la dinámica política del país; pero también sugieren que este proceso no se considera como un evento de transformación fundamental, al menos no de manera radical. Una elección de cambio, en el sentido estricto, hubiese registrado una recuperación en los niveles de participación ciudadana, e involucrado con interés a segmentos importantes de la población salvadoreña pero, sobre todo, hubiese dado la victoria de una manera inobjetable al FMLN como opción alternativa de poder. Por el contrario, el número de votos fue menor en esta ocasión que en el pasado, y la mayoría de la población -los más pobres y menos educados- superó el proceso electoral sin complicarse con él, así el partido de gobierno consiguió mantenerse - aunque con escaso margen- a la cabeza de las preferencias electorales. Con todo, ARENA, el partido gobernante, mantuvo su posición de partido con más votos a su favor $y$, aunque en una posición frágil, nadie puede menospreciar su resistencia para mantenerse en el primer lugar de las opciones electorales en una coyuntura claramente desfavorable por su desgaste al frente del gobierno.

Más que un voto de transformación, el evento electoral recién pasado ha sido una sentencia de equilibrio, tanto por aquéllos que se decidieron a votar y lo hicieron repartiendo sus opciones esencialmente entre los polos, como por quienes decidieron no hacerlo debido a la desconfianza en el sistema político partidario electoral. Tener en cuenta este hecho es muy importante para entender la conducta electoral recién pasada y futura. Un público convencido de la necesidad del cambio no es un conjunto social apático sino comprometido políticamente. La apatía electoral existe cuando el sistema político, tal y como está planteado, no representa novedad alguna para la población; los ciudadanos no votan porque ninguna opción representa sus aspiraciones o porque sus expectativas se cumplen en el statu quo.

Lo anterior plantea el último hecho que se señala en este comentario: antes que considerar a las pasadas elecciones como una muestra de apoyo incondicional hacia la izquierda o como un voto de rechazo hacia ARENA, se deben considerar a las mismas como una demostración de la desconfianza que tienen los salvadoreños hacia sus partidos y hacia su sistema político. Con esta afirmación no se trata de menospreciar el significativo avance del FMLN o de soslayar el desgaste del partido en el gobierno. Ambas cosas tienen su importancia, pero desde la perspectiva de la conducta electoral, los resultados indican que la ciudadanía que votó y la que no lo hizo, buscó de manera simultánea, restar el enorme potencial que detentaba ARENA y brindar espacio suficiente al FMLN para que tuviera finalmente una oportunidad en la conducción del país. Por un lado, la gente votó por ARENA para mantenerlo donde está, pero al mismo tiempo restándole poder político; por otro lado, la gente votó por el FMLN para colocarlo en igualdad de condiciones sin que se impusiera sobre sus adversarios. En otras palabras, los ciudadanos que asistieron a las urnas como los que no lo hicieron, provocó que ninguno de los partidos recibiera el apoyo necesario para controlar la dinámica política en la asamblea y en los gobiernos municipales del país: amarrar a todos los partidos entre sí y, en la actualidad, ninguno puede llevar a cabo sus iniciativas fundamentales si no cuenta con el consentimiento mínimo del resto.

De esta forma, ningún partido puede erijirse como el único representante de las aspiraciones populares. Lejos de enviar mensajes equívocos de apoyo incondicional a los partidos, los ciudadanos han decidido mostrar su desconfianza, obligándolos a controlarse entre sf y concertar sus iniciativas políticas nacionales. En tal sentido, y paradojicamente, la supervivencia política de los partidos salvadoreños de cara a las elecciones presidenciales no depende tanto de la firmeza con que lleven a cabo sus iniciativas políticas, sino de la habilidad para concertar un proyecto de nación en donde todos los partidos y la sociedad se vean involucrados. Este es el reto al final de la transición. El presidente electo en 1999 probablemente 
será el candidato que mejor refleje las habilidades de su partido para concertar un proyecto participativo de nación. En la medida en que los partidos comprendan este mensaje entenderán que su futuro político depende ahora de la tolerancia y la participación de todos los sectores de la sociedad, no de unos pocos.

Una interpretación adecuada del evento electoral de este año puede ser útil para cambiar el rumbo del país a través de una transformación en la manera de hacer política. Para la mayoría de sal- vadoreños, las elecciones de marzo de 1997 han significado el "tocar fondo" dentro de la incipiente estabilidad social que vive el país; en la medida en que lo comprenda la clase política, y deje de lado los triunfalismos, los espejismos optimistas y la soberbia de quienes creen que el país está muy bien, en esa medida se estará frente a la última oportunidad de sacar al país de la crisis social en la cual se encuentra inmerso. 